\title{
Regulatory effect of miR-144-3p on the function of human trabecular meshwork cells and fibronectin-1
}

\author{
RUOXI YIN $^{1}$ and XIAOYA CHEN ${ }^{2}$ \\ ${ }^{1}$ Postgraduate School, Xuzhou Medical University; ${ }^{2}$ Department of Ophthalmology, Xuzhou No. 1 People's Hospital, \\ Xuzhou Municipal Hospital Affiliated to Xuzhou Medical University, Xuzhou Eye Hospital, \\ Xuzhou, Jiangsu 221000, P.R. China
}

Received January 21, 2019; Accepted April 23, 2019

DOI: $10.3892 / \mathrm{etm} .2019 .7584$

\begin{abstract}
Role of microRNA (miR)-144-3p in regulating the function of human trabecular meshwork cells (HTMCs) and fibronectin-1 (FN-1) was investigated. HTM cell lines were divided into five groups, of which four groups established oxidative stress HTMC models and one served as a control group. The four model groups were transfected with miR-144-3p independent sequence, inhibitory sequence, over-expression sequence, and the blank group received no transfection. In addition, 40 primary open angle glaucoma patients treated in Xuzhou No. 1 People's Hospital were included in the observation group, and 40 healthy individuals were enrolled as a normal group. RT-qPCR was used for the detection of miR-144-3p expression in serum and cells of patients and healthy people in each group, western blot analysis for FN-1 expression in cells, CCK-8 kit for cell proliferation, and Transwell for cell invasion. The expression of serum miR-144-3p in the observation group was significantly lower than that in the normal group $(\mathrm{P}<0.05)$. The cell optical density value in the over-expression group was significantly higher than that in the other groups $(\mathrm{P}<0.05)$, and in the inhibition group was significantly lower than that in the other groups $(\mathrm{P}<0.05)$. The number of cell-penetration in the over-expression group was significantly higher than that in the other groups $(\mathrm{P}<0.05)$. The expression of $\mathrm{FN}-1$ protein in the over-expression group was significantly lower than that in the other four groups $(\mathrm{P}<0.05)$, and the expression in the inhibition group was significantly higher than that in the other four groups $(\mathrm{P}<0.05)$. The over-expression of miR-144-3p promotes proliferation and invasion of HTMCs by inhibiting
\end{abstract}

Correspondence to: Dr Xiaoya Chen, Department of Ophthalmology, Xuzhou No. 1 People's Hospital, Xuzhou Municipal Hospital Affiliated to Xuzhou Medical University, Xuzhou Eye Hospital, 17 Zhongshan North Road, Xuzhou, Jiangsu 221000, P.R. China

E-mail:rx620e@163.com; xiaoya-chen@163.com

Key words: miR-144-3p, glaucoma, human trabecular meshwork cells, fibronectin-1, proliferation, invasion the expression of FN-1 in inoxidative stress HTMCs, and is a potential target for glaucoma treatment.

\section{Introduction}

Glaucoma, one of the three major eye diseases that lead to blindness, is caused by the depression and atrophy of optic papilla (1). In recent years, it has been found that approximately 60 million individuals suffer from open angle or angle-closure glaucoma worldwide, and glaucoma is second only to cataract in causing blindness to patients (2). Primary open angle glaucoma (POAG) is one of the most common glaucoma types with the clinical manifestations of pathological intraocular pressure (IOP) elevation which causes optic nerve blood supply insufficiency in patients (3). Previous findings showed that elevated IOP is closely related to increased aqueous outflow resistance in trabecular meshwork, and the main function of trabecular meshwork is to control the aqueous flow direction (4). Another study has shown that the abnormal deposition of extracellular matrix (ECM) is the main factor causing increased aqueous outflow resistance in trabecular meshwork and elevated IOP (5).

Being a hot research field in recent years, microRNA $(\mathrm{miR})$ is a kind of non-coding short-chain RNA with a length of approximately 22 nucleotides that functions mainly to inhibit the translation and transcription of a target gene by binding to the 3' untranslated region (UTR) of its cognate mRNA, thereby changing the expression of the gene (6). Increasing number of studies have shown that miR is closely related to tumor and cardiovascular diseases $(7,8)$. Moreover, there are related studies showing that miR is related to glaucoma. The study of Zhang et al (9) has shown that reduced miR-187 expression in retinal cells promotes Smad7 expression and induces retinal ganglion cells (RGCs) apoptosis in patients with glaucoma. Current research shows that, miR-144-3p is one of the important members of the miR family $(10,11)$. It is differentially expressed in a variety of tumors and cardiovascular diseases, and is closely related to the progression of these diseases. Fibronectin-1 (FN-1), also known as FN, is a high-molecular-weight glycoprotein that can regulate various biological functions and widely exists in animal tissues and tissue fluids (12). A study has shown that, the expression of FN-1 protein is increased in 
ECM of human trabecular meshwork cells (HTMCs) in POAG patients, and FN can promote ECM deposition to block trabecular meshwork, thereby causing an increase in pathological IOP (13). However, according to Liang et al (14), the luciferase reporter gene confirms that miR-144-3p can targetly regulate FN-1 expression. However, it is not clear whether miR-144-3p is differentially expressed in glaucoma patients, or it can regulate the function of HTMCs and the role of $\mathrm{FN}-1$.

Therefore, this study explored the regulatory effects of miR-144-3p on HTMC proliferation, invasion and FN-1, thus providing a reference for clinicians.

\section{Materials and methods}

Cell source. HTMCs (BNCC342361; BeNa Culture Collection Company, Beijing, China).

Main kits and instruments. TRIzol Extraction kit, RIPA, BCA Protein kit,Lipofectamine ${ }^{\mathrm{TM}}$ 2000, ECL Luminescence kit, Transwell kit (nos. 15596018, 89900, 23225, 11668030, 35055, A1142801; Thermo Fisher Scientific, Inc., Shanghai, China); $\mathrm{H}_{2} \mathrm{O}_{2}$, FBS, DMEM, Penicillin-streptomycin double-antibody (216763, F2442, D5796, V900929; Sigma-Aldrich; Merck KGaA, Darmstadt, Germany); RT-qPCR kit, TransScript Green miRNA Two-Step RT-qPCR SuperMix (AQ202-01; Beijing TransGen Biotech Co., Ltd., Beijing, China), FN-1 monoclonal antibody, $\beta$-actin monoclonal antibody, horseradish peroxidase (HRP)-labeled goat anti-mouse IgG secondary antibody (nos. MAB19182, MAB8929, HAF007; R\&D Systems, Inc., Minneapolis, MN, USA), CCK-8 kit (C0037; Beyotime Institute of Biotechnology, Shanghai, China), miR-144-3p primer sequence, inhibition and over-expression sequences, and independence sequence were designed and produced by Sangon Biotech Co., Ltd. (Shanghai, China).

Cell culture. The HTMCs were placed in DMEM medium (10\% FBS, penicillin-streptomycin double-antibody) and transferred to an incubator containing $5 \% \mathrm{CO}_{2}$ at $37^{\circ} \mathrm{C}$. The solution was changed every 2 days and $0.25 \%$ trypsin was used for digestion and passage when the cell fusion reached approximately $90 \%$.

Modeling and grouping. The 3rd-4th generation cells were collected and the density was adjusted to $4 \times 10^{6}$, then inoculated in a 6 -well plate. Oxidative stress models were established $24 \mathrm{~h}$ later, and the cells were cultured in a $37^{\circ} \mathrm{C}$ constant temperature incubator with $300 \mu \mathrm{M} \mathrm{H}_{2} \mathrm{O}_{2}$ serum-free DMEM medium for $2 \mathrm{~h}$. There were 5 groups in this experiment: the control, the blank, the independence sequence, the over-expression and the inhibition groups. The cells in the control group were not cultured with $\mathrm{H}_{2} \mathrm{O}_{2}$, while the blank, the independence sequence, the over-expression and the inhibition groups all used $\mathrm{H}_{2} \mathrm{O}_{2}$ for induction culture. Additionally, the cells in the independence sequence, the over-expression and the inhibition groups were transferred to corresponding sequence plasmids respectively using Lipofectamine 2000. The procedure was carried out according to the protocol and the cells were cultured in an incubator for $2 \mathrm{~h}$.
Clinical data of patients. A total of 40 POAG patients treated in Xuzhou No. 1 People's Hospital (Xuzhou, China) were included into the observation group, including 25 males and 15 females with an average age of $45.24 \pm 8.23$ years, and they all underwent systematic ophthalmological examinations, including optometry, best corrected visual acuity (BCVA), slit lamp, fundus examination, IOP measurement, gonioscopy, visual field and visual evoked potential (VEP) tests. Another 40 healthy people with normal visual acuity, heart, lung, liver and kidney laboratory tests were collected as a normal group, including 22 males and 18 females with an average age of $46.22 \pm 7.69$ years. There was no difference in sex and age between the two groups $(\mathrm{P}>0.05)$. Inclusion criteria were: i) patients with complete clinical data; ii) patients with no family history of glaucoma; and iii) patients conforming to Diagnosis and Treatment of Primary Glaucoma Consensus in China. Exclusion criteria were: i) patients complicated with malignant tumor; ii) patients with cardio-cerebrovascular disease; iii) patients receiving glaucoma treatment before this test; and iv) patients with no previous operation history caused atrial morphological changes and liver fibrosis.

The study was approved by the Ethics Committee of Xuzhou Medical University (Xuzhou, China). Patients who participated in this study had complete clinical data. Signed informed consents were obtained from the patients or the guardians.

Sample collection. Fasting venous blood samples $(5 \mathrm{ml})$ of patients in the two groups were collected in the morning, left to stand for $30 \mathrm{~min}$, and centrifuged at $1,509.3 \mathrm{x}$ g for $10 \mathrm{~min}$ at $25^{\circ} \mathrm{C}$. The serum was collected for follow-up experiments.

RT-qPCR detection. Total RNAs were extracted from the patient serum and the cells of each group after $2 \mathrm{~h}$ of transfection and culture using the TRIzol extraction reagent. The purity, concentration and integrity of total RNAs were detected using an ultraviolet spectrophotometer and $1 \%$ agarose gel electrophoresis. The total RNA was reverse transcribed into cDNA using 2X TS miRNA Reaction Mix in TransScript Green miRNA Two-Step RT-qPCR SuperMix, and the specific operation steps were carried out according to the manufacturer's protocol. Then PCR amplification experiment was carried out for the PCR reaction system: $1 \mu \mathrm{l}$ of cDNA, $0.4 \mu \mathrm{l}$ of each upstream and downstream primers (Table I), $10 \mu \mathrm{l}$ of $2 \mathrm{X}$ TransTaq ${ }^{\circledR}$ Tip Green qPCR SuperMix, $0.4 \mu 1$ of Passive Reference Dye (50X), made up to $20 \mu \mathrm{l}$ with $\mathrm{ddH}_{2} \mathrm{O}$. PCR reaction conditions were: pre-denaturation at $94^{\circ} \mathrm{C}$ for $30 \mathrm{sec}$, denaturation at $94^{\circ} \mathrm{C}$ for $5 \mathrm{sec}$, annealing at $60^{\circ} \mathrm{C}$ for $15 \mathrm{sec}$, extension at $72^{\circ} \mathrm{C}$ for $10 \mathrm{sec}$, for a total of 40 cycles. Each sample was tested in 3 repeat wells, and the experiment was carried out 3 times. In this study, U6 was used as an internal reference and $2^{-\Delta \Delta \mathrm{Cq}}$ was used to analyze the data (15). $\beta$-actin was used as the internal reference in this study.

Western blot $(W B)$ detection. Total protein was extracted from the collected cells using the RIPA lysis method, and its concentration was detected with the bicinchoninic acid (BCA) method and adjusted to $4 \mu \mathrm{g} / \mu \mathrm{l}$. The proteins were separated by $12 \%$ SDS-PAGE and then transferred to a polyvinylidene difluoride membrane. The membrane was 
Table I. Primer sequence.

\begin{tabular}{lll}
\hline Gene & Upstream primer & Downstream primer \\
\hline miR-144-3p & 5'-CCCTACAGTATAGATGATG-3' & 5'-TGCAGGGTCCGAGGT-3' \\
U6 & 5'-TAGGGTGCTCGCTTCGGC-3' & 5'-CTGGTGTCGTGGAGTCG-3' \\
\hline
\end{tabular}

miR, microRNA.

stained with Ponceau $\mathrm{S}$ working solution, immersed in PBS for $5 \mathrm{~min}$ and then washed, blocked with $5 \%$ skimmed milk powder for $2 \mathrm{~h}$, and finally incubated overnight at $4^{\circ} \mathrm{C}$ with the primary antibodies $(1: 1,000)$. Following washing to remove primary antibodies ( $\mathrm{FN}-1$ and $\beta$-actin monoclonal antibody), the HRP-labeled goat anti-mouse secondary antibody $(1: 5,000)$ was added to the membrane for a $1 \mathrm{~h}$ incubation at $37^{\circ} \mathrm{C}$. After that, the membrane was rinsed 3 times with PBS, for $5 \mathrm{~min}$ each time. The protein bands on the membrane were developed in the dark using the enhanced chemiluminescence (ECL) reagent, and the excess liquid on the membrane was absorbed with a filter paper. The luminescent protein bands were scanned and the gray value was analyzed using Quantity One software. The relative expression level of each protein was: the gray value of the target protein band/the gray value of the $\beta$-actin protein band.

Cell proliferation detection. The 3rd-4th generation cells were collected and the density was adjusted to $4 \times 10^{6}$, then inoculated in a 6-well plate. Oxidative stress models were established after $24 \mathrm{~h}$ and the cells were transfected, then cultured for $48 \mathrm{~h}$ and $10 \mu \mathrm{l}$ of CCK solution and $90 \mu \mathrm{l}$ basal medium (DMEM) were added to each well, and cultured at $37^{\circ} \mathrm{C}$ for $2 \mathrm{~h}$. The optical density (OD) value of cells in each group was tested at $570 \mathrm{~nm}$ absorbance using a microplate reader.

Cell invasion detection. Transwell chamber was placed in a 24-well plate, $500 \mu \mathrm{l}$ DMEM culture solution was added to the upper chamber, and $100 \mu \mathrm{l}$ DMEM was added to the lower chamber, then the cells were cultured for $1 \mathrm{~h}\left(37^{\circ} \mathrm{C}\right)$. The 3 rd-4th generation cells were collected and the density was adjusted to $4 \times 10^{6}$, then inoculated in a 6 -well plate. Oxidative stress models were established after $24 \mathrm{~h}$ and the cells were transfected, digested and resuspended with $0.25 \%$ trypsin, then added into a serum-free DMEM medium. The cells then were inoculated in a 24-well plate, and the density was adjusted by $1.5 \times 10^{6}$ cells. The Transwell chamber was taken out, the lower chamber was replaced with $100 \%$ FBS, and $100 \mu$ l cell suspension was added into the upper one, then the cells were incubated at $37^{\circ} \mathrm{C}$ for $10 \mathrm{~h}$. The substrates and cells that did not penetrate the membrane surface in the upper chamber were wiped off, washed three times with PBS, fixed with paraformaldehyde for $10 \mathrm{~min}$, flushed three times with double-distilled water, dyed with $0.1 \%$ crystal violet for 10 min after drying, then rinsed three times with double-distilled water. A microscope was used to observe the cell invasion.

Statistical analysis. In this study, SPSS20.0 (Cabit Information Technology Co., Ltd., Shanghai, China) software package was

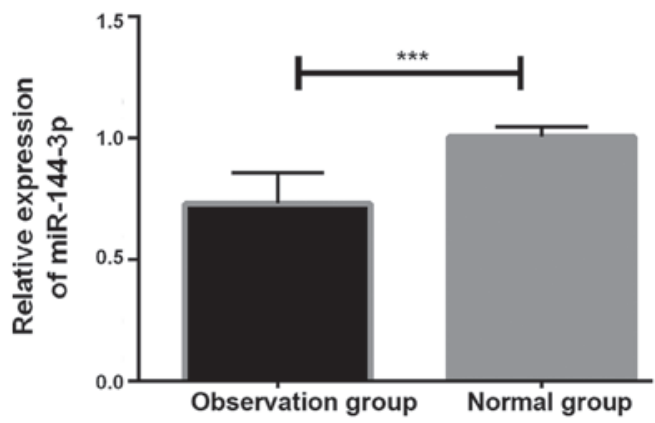

Figure 1. Expression of serum miR-144-3p in the observation and normal groups. Expression of serum miR-144-3p in the two groups detected by RT-qPCR showed that the expression in the normal group was significantly higher than that in the observation group. ${ }^{* * *} \mathrm{P}<0.001$, significant difference between the two groups. miR, microRNA.

used to carry out statistical analysis on the collected data. GraphPad Prism 7 (Soft Head Technology Co., Ltd., Shenzhen, China) was used to draw the data figure. The measurement data were expressed as mean \pm standard deviation. The comparison between the two groups was carried out by independent sample t-test, and denoted by t. The comparison between multiple groups was carried out by variance analysis, and denoted by $\mathrm{F}$, and the the pairwise comparison was carried out by LSD-t-test afterwards. $\mathrm{P}<0.05$ was considered to indicate a statistically significant difference between the two groups.

\section{Results}

Expression of miR-144-3P in serum of patients. By detecting the expression of miR-144-3p in serum of the patients, it was found that the expression in the normal group was significantly higher than that in the observation group, with significant differences $(\mathrm{P}<0.001$; Fig. 1).

Expression of miR-144-3p in transfected cells. The detection of miR-144-p expression in cells of each group after transfection showed that there was a significant difference in the expression of miR-144-3p among groups $(\mathrm{F}=100.954, \mathrm{P}<0.001)$. The expression in the control group was significantly higher than that in the blank, the independence sequence and the inhibition groups, but significantly lower than that in the over-expression group $(\mathrm{P}<0.05)$. While the expression in blank and independence sequence groups was significantly higher than that in the inhibition group but lower than that in control and the over-expression groups $(\mathrm{P}<0.05)$. There was no significant difference between the blank and the independence sequence groups ( $\mathrm{P}>0.05)$. However, the expression of miR-144-p in the 
Table II. Expression of miR-144-3p in cells of each group.

\begin{tabular}{llll}
\hline Group & miR-144-3p & F & P-value \\
\hline Control & $1.450 \pm 0.102$ & & \\
Blank & $1.032 \pm 0.042^{\mathrm{a}}$ & & \\
Independence sequence & $1.055 \pm 0.010^{\mathrm{a}}$ & 100.954 & $<0.001$ \\
Inhibition & $0.350 \pm 0.067^{\mathrm{a}-\mathrm{c}}$ & & \\
Over-expression & $7.167 \pm 1.07^{\mathrm{a}-\mathrm{d}}$ & & \\
& & &
\end{tabular}

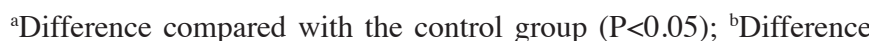
compared with the blank group $(\mathrm{P}<0.05)$; ${ }^{\mathrm{c}}$ Difference compared with the independence sequence group $(\mathrm{P}<0.05)$; ${ }^{\mathrm{D}}$ Difference compared with the inhibition group $(\mathrm{P}<0.05)$. miR, microRNA.

Table III. Cell proliferation in each group after $48 \mathrm{~h}$.

\begin{tabular}{llll}
\hline Group & OD value & F & P-value \\
\hline Control & $0.842 \pm 0.115$ & & \\
Blank & $0.622 \pm 0.084^{\mathrm{a}}$ & & \\
Independence sequence & $0.634 \pm 0.092^{\mathrm{a}}$ & 29.146 & $<0.001$ \\
Inhibition & $0.325 \pm 0.055^{\mathrm{a}-\mathrm{c}}$ & & \\
Over-expression & $1.241 \pm 0.165^{\mathrm{a}-\mathrm{d}}$ & & \\
\hline
\end{tabular}

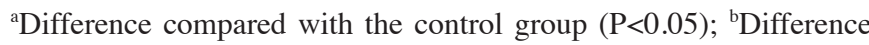
compared with the blank group $(\mathrm{P}<0.05)$; ${ }^{\mathrm{C}}$ Difference compared with the independence sequence group $(\mathrm{P}<0.05)$; ${ }^{\mathrm{d}}$ Difference compared with the inhibition group $(\mathrm{P}<0.05)$. OD, optical density.

Table IV. Cell-penetration in each group.

\begin{tabular}{lccc}
\hline Group & $\begin{array}{c}\text { No. of } \\
\text { cell-penetration }\end{array}$ & F & P-value \\
\hline Control & $139.54 \pm 11.66$ & & \\
Blank & $115.88 \pm 9.45^{\mathrm{a}}$ & & \\
Independence sequence & $109.75 \pm 8.77^{\mathrm{a}}$ & 52.656 & $<0.001$ \\
Inhibition & $57.95 \pm 9.44^{\mathrm{a}-\mathrm{c}}$ & & \\
Over-expression & $188.15 \pm 15.74^{\mathrm{a}-\mathrm{d}}$ & & \\
& & & \\
\hline
\end{tabular}

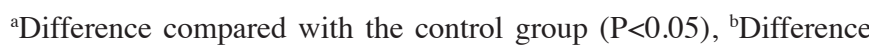
compared with the blank group $(\mathrm{P}<0.05)$, ${ }^{\mathrm{C}}$ Difference compared with the independence sequence group $(\mathrm{P}<0.05)$, ${ }^{\mathrm{d}}$ Difference compared with the inhibition group $(\mathrm{P}<0.05)$.

inhibitory group was significantly lower than that in the other four groups $(\mathrm{P}<0.05)$, and the expression in the over-expression group was significantly higher than that in other four groups $(\mathrm{P}<0.05$; Table II).

Cell proliferation in each group after $48 \mathrm{~h}$. The comparison of OD value among the five groups of cells cultured for $48 \mathrm{~h}$ showed that there was a significant difference in cell proliferation among groups $(\mathrm{F}=29.146, \mathrm{P}<0.001)$. The value in the over-expression group was significantly higher than

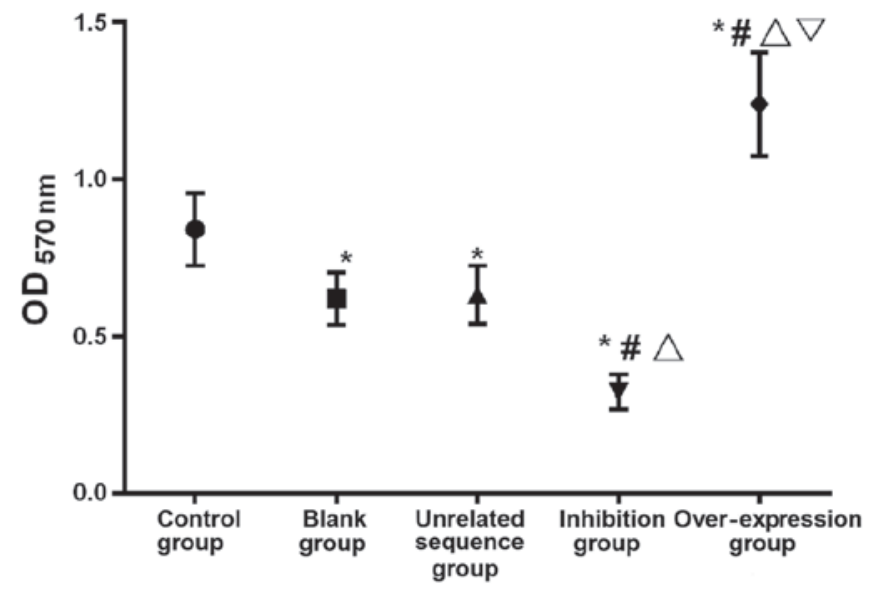

Figure 2. OD value of cells in each group after $48 \mathrm{~h}$ of transfection. Cell proliferation detected by CCK- 8 assay showed that the OD value in the over-expression group was significantly higher than that in the other groups $(\mathrm{P}<0.05)$, and in the inhibition group was significantly lower than that in the other groups $(\mathrm{P}<0.05)$. There was no difference between the blank and the independence sequence groups $(\mathrm{P}>0.05)$, while the $\mathrm{OD}$ value in these two groups was significantly higher than that in the inhibition group but lower than that in the control and the over-expression groups $(\mathrm{P}<0.05)$. ${ }^{*} \mathrm{P}<0.05$, difference compared with the control group; ${ }^{\#} \mathrm{P}<0.05$, difference compared with the blank group; ${ }^{\wedge} \mathrm{P}<0.05$, difference compared with the independence sequence group; ${ }^{\nabla} \mathrm{P}<0.05$, difference compared with the inhibition group. miR, microRNA; OD, optical density.

that in the other groups $(\mathrm{P}<0.05)$, and in the inhibition group was significantly lower than that in the other groups $(\mathrm{P}<0.05)$. There was no difference between the blank and the independence sequence groups $(\mathrm{P}>0.05)$, while the $\mathrm{OD}$ value in these two groups was significantly higher than that in the inhibition group but lower than that in the control and the over-expression groups $(\mathrm{P}<0.05$; Table III and Fig. 2).

Cell invasion. The number of cell-penetration in each group was counted and found that there was a significant difference in the number of cell-penetration among groups $(\mathrm{F}=52.656$, $\mathrm{P}<0.001)$. The number in the over-expression group was significantly higher than that in other groups $(\mathrm{P}<0.05)$, and that in the inhibition group had the least compared with the other four groups $(\mathrm{P}<0.05)$. There was no significant difference in the number of cell-penetration between the blank and the independence sequence groups $(P>0.05)$, and the number in these two groups significantly decreased compared with the control and the over-expression groups, but significantly increased compared with the inhibition group $(\mathrm{P}<0.05$; Table IV and Fig. 3).

Expression of $F N-1$ protein. The expression of $\mathrm{FN}-1$ protein in cells of each group was detected, and the results of Western blotting showed that there was a significant difference in the expression of $\mathrm{FN}-1$ among groups $(\mathrm{F}=25.611, \mathrm{P}<0.001)$. The expression in the over-expression group was significantly lower than that in the other four groups $(\mathrm{P}<0.05)$. The expression in the blank and the independence sequence groups had no significant difference $(\mathrm{P}>0.05)$, but was significantly higher than that in the control and the over-expression groups and significantly lower than that in the inhibition group $(\mathrm{P}<0.05)$. The expression of FN-1 protein in the inhibition group was 
Table V. Comparison of FN-1 protein.

\begin{tabular}{lllll}
\hline Group & $\begin{array}{c}\text { Relative expression } \\
\text { of FN-1 protein }\end{array}$ & F & P-value \\
\hline Control & $0.684 \pm 0.054$ & & \\
Blank & $0.925 \pm 0.112^{\mathrm{a}}$ & & \\
Independence sequence & $0.930 \pm 0.160^{\mathrm{a}}$ & $25.611<0.001$ \\
Inhibition & $1.354 \pm 0.147^{\mathrm{a}-\mathrm{c}}$ & & \\
Over-expression & $0.459 \pm 0.049^{\mathrm{a}-\mathrm{d}}$ & & \\
\hline
\end{tabular}

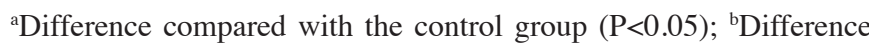
compared with the blan k group $(\mathrm{P}<0.05)$; ${ }^{\circ}$ Difference compared with the independence sequence group $(\mathrm{P}<0.05)$; ${ }^{\mathrm{d}}$ Difference compared with the inhibition group $(\mathrm{P}<0.05)$. FN-1, fibronectin-1.

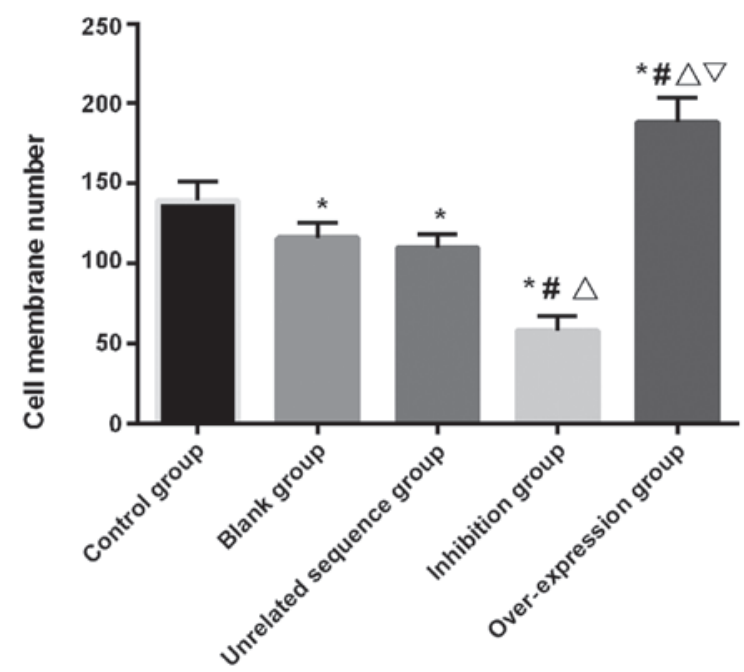

Figure 3. Cell invasion in each group after transfection. Cell invasion detected by Transwell assay showed that the number of cell-penetration in the over-expression group was significantly higher than that in the other groups $(\mathrm{P}<0.05)$, and that in the inhibition group was the least compared with the other four groups $(\mathrm{P}<0.05)$. There was no significant difference in the number of cell-penetration between the blank and independence sequence groups $(\mathrm{P}>0.05)$, and the number in these two groups significantly decreased compared with the control and over-expression groups, but significantly increased compared with the inhibition group $(\mathrm{P}<0.05)$. " $\mathrm{P}<0.05$, difference compared with the control group; ${ }^{\#} \mathrm{P}<0.05$, difference compared with the blank group; ${ }^{\wedge} \mathrm{P}<0.05$, difference compared with the independence sequence group; ${ }^{\triangleright} \mathrm{P}<0.05$, difference compared with the inhibition group.

significantly higher than that in the other four groups $(\mathrm{P}<0.05$; Table V and Fig. 4).

\section{Discussion}

Glaucoma is a serious and irreversible blinding eye disease, of which POAG is the most common type. However, each type can cause retinal ganglion cell damage (16). The clinical pathological manifestations of glaucoma are mainly elevated IOP caused by excessive aqueous humor. Therefore, the main way to treat glaucoma is to reduce aqueous humor secretion or aqueous outflow resistance (5). Trabecular meshwork, an important part of aqueous humor circulation, mainly regulates ECM and aqueous outflow (17).

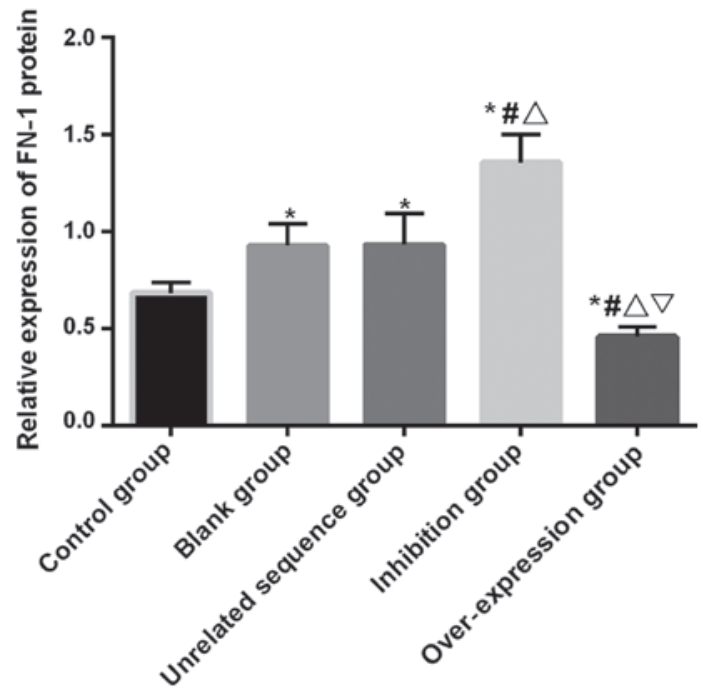

Figure 4. Relative expression of FN-1 protein in each group after transfection. Relative expression of FN-1 protein in cells detected by WB showed that the expression in the over-expression group was significantly lower than that in the other four groups $(\mathrm{P}<0.05)$. The expression in the blank and the independence sequence groups had no significant difference $(P>0.05)$, but was significantly higher than that in the control and over-expression groups and significantly lower than that in the inhibition group $(\mathrm{P}<0.05)$. The expression of $\mathrm{FN}-1$ protein in the inhibition group was significantly higher than that in the other four groups $(\mathrm{P}<0.05)$. ${ }^{*} \mathrm{P}<0.05$, difference compared with the control group; ${ }^{\#} \mathrm{P}<0.05$, difference compared with the blank group; ${ }^{\triangle} \mathrm{P}<0.05$, difference compared with the independence sequence group; ${ }^{\nabla} \mathrm{P}<0.05$, difference compared with the inhibition group. FN-1, fibronectin-1.

As a hot research field in recent years, miR has been shown to be closely related to diseases such as glaucoma $(18,19)$. Being an important member of the miR family, miR-144-3p plays a role in the miR-451 gene cluster and can also regulate the expression of a plurality of genes involved in erythropoiesis (20). It was shown that miR-144 is a potential therapeutic tool for treating ischemic heart disease (21). By contrast, Liu et al (22) showed that miR-144 was under-expressed in liver fibrosis cells. It is well known that fibrosis is an over-reaction in wound healing, which leads to excessive ECM that can be reduced by miR-144 regulating TGF- $\beta 1$ expression. ECM deposition also occurs after HTMCs are damaged in glaucoma. However, whether miR-144-3p has the same expression in glaucoma patients has not yet been studied. Therefore, this study provided reference for treatment by exploring the effect of miR-144-3p on HTMCs and its expression in the serum of glaucoma patients.

Research has shown that there is a close relationship between chronic oxidative stress and the occurrence and development of trabecular meshwork lesions (23). Elevated IOP decreased blood flow velocity in glaucoma patients, resulting in the decrease of oxygen flow rate, thus keeping HTMCs in a hypoxic state. Therefore, in this study, HTMC oxidative stress models were established and the expression of miR-144-3p in HTMCs was detected. The results showed that the expression of miR-144-3p in the modeled cells was significantly lower than that in the control group without modeling, and the clinical detection showed that the expression in serum of normal people was significantly higher than that of glaucoma patients, indicating that miR-144-3p is expected to become a potential diagnostic indicator for glaucoma. FN-1, as a non-collagen a2 glycoprotein, participates in cell-to-cell and cell-to-matrix adhesion in the body (24). 
Babizhayev and Brodskaya (25) showed that there was a large amount of FN-1 deposition in the trabecular meshwork adjacent area and the Schlemm inner wall of HTMCs in POAG patients, and the deposition increased with the aggravation of the disease. By detecting the expression of FN-1 mRNA and protein in the cells after modeling, it was found that the expression in the blank group was significantly higher than that in the control group, which was basically similar to the expression of FN-1 in the HTMCs induced by glucocorticoid dexamethasone as indicated by Filla et al (26). However, it is not clear whether there is a connection between miR-144-3p and FN-1 protein. Therefore, Targetscan, an online miR target gene prediction software, was used in that study, and it was found that there were possible binding targets between miR-144-3p and FN-1 (26). Moreover, Liang et al (14) confirmed their relationship using double luciferase report. The expression detection of $\mathrm{FN}-1$ protein in cells of each group found that the expression of miR-144-3p in cells of the over-expression group was significantly higher than that of the blank and the independence sequence groups, while the expression of FN-1 protein was significantly lower than that of the two groups. In contrast, the expression of miR-144-3p in cells of the inhibition group was significantly lower than that of the blank and the independence sequence groups, while the expression of FN-1 protein was significantly higher than that of the two groups. These results suggest that the over-expression of miR-144-3p reduces the expression of $\mathrm{FN}-1$ protein in cells of trabecular meshwork oxidative stress models. Moreover, the detection showed that the proliferation and invasion of cells after modeling in the over-expression group were significantly enhanced compared with the other groups, which indicates that over-expression of miR-144-3p can upregulate the proliferation and migration of HTMCs.

This study proved the expression of miR-144-3p in oxidative stress HTMCs and its role in regulating FN-1. However, there were still some limitations. First, a double luciferase experiment was not carried out. Although it has been confirmed in other studies, it is not clear whether there is any difference caused by the two different research directions. Second, this study served as a basic experiment, and whether miR-144-3p can be used as a potential target for clinical treatment of glaucoma has not been verified. Therefore, relevant experiments are to be carried out in clinic to confirm the potential value of miR-144-3p in the treatment of glaucoma.

To sum up, the over-expression of miR-144-3p promotes the proliferation and invasion of HTMCs by inhibiting the expression of FN-1 in oxidative stress HTMCs, and is a potential target for glaucoma treatment.

\section{Acknowledgements}

Not applicable.

\section{Funding}

No funding was received.

\section{Availability of data and materials}

The datasets used and/or analyzed during the present study are available from the corresponding author on reasonable request.

\section{Authors' contributions}

RY wrote the manuscript. XC performed PCR. RY was responsible for western blot analysis and Transwell. XC contributed to analysis of observation indexes. Both authors read and approved the final manuscript.

\section{Ethics approval and consent to participate}

The study was approved by the Ethics Committee of Xuzhou Medical University (Xuzhou, China). Patients who participated in this study had complete clinical data. Signed informed consents were obtained from the patients or the guardians.

\section{Patient consent for publication}

Not applicable.

\section{Competing interests}

The authors declare that they have no competing interests.

\section{References}

1. Zetterberg M: Age-related eye disease and gender. Maturitas 83: 19-26, 2016.

2. Quigley HA and Broman AT: The number of people with glaucoma worldwide in 2010 and 2020. Br J Ophthalmol 90: 262-267, 2006.

3. Kapetanakis VV, Chan MP, Foster PJ, Cook DG, Owen CG and Rudnicka AR: Global variations and time trends in the prevalence of primary open angle glaucoma (POAG): A systematic review and meta-analysis. Br J Ophthalmol 100: 86-93, 2016.

4. Tamm ER, Braunger BM and Fuchshofer R: Intraocular pressure and the mechanisms involved in resistance of the aqueous humor flow in the trabecular meshwork outflow pathways. Prog Mol Biol Transl Sci 134: 301-314, 2015.

5. Braunger BM, Fuchshofer R and Tamm ER: The aqueous humor outflow pathways in glaucoma: A unifying concept of disease mechanisms and causative treatment. Eur J Pharm Biopharm 95 (Pt B): 173-181, 2015.

6. Ha M and Kim VN: Regulation of microRNA biogenesis. Nat Rev Mol Cell Biol 15: 509-524, 2014.

7. Lin S and Gregory RI: MicroRNA biogenesis pathways in cancer. Nat Rev Cancer 15: 321-333, 2015.

8. Condorelli G, Latronico MV and Cavarretta E: microRNAs in cardiovascular diseases: Current knowledge and the road ahead. J Am Coll Cardiol 63: 2177-2187, 2014.

9. Zhang QL, Wang W, Li J, Tian SY and Zhang TZ: Decreased miR-187 induces retinal ganglion cell apoptosis through upregulating SMAD7 in glaucoma. Biomed Pharmacother 75: 19-25, 2015 .

10. Zhang SY, Lu ZM, Lin YF, Chen LS, Luo XN, Song XH, Chen SH and Wu YL: miR-144-3p, a tumor suppressive microRNA targeting ETS-1 in laryngeal squamous cell carcinoma. Oncotarget 7: 11637-11650, 2016

11. Chen B, Luo L, Wei X, Gong D and Jin L: Altered plasma miR-144 as a novel biomarker for coronary artery disease. Ann Clin Lab Sci 48: 440-445, 2018.

12. Pankov R and Yamada KM: Fibronectin at a glance. J Cell Sci 115: 3861-3863, 2002.

13. Medina-Ortiz WE, Belmares R, Neubauer S, Wordinger RJ and Clark AF: Cellular fibronectin expression in human trabecular meshwork and induction by transforming growth factor- $\beta 2$. Invest Ophthalmol Vis Sci 54: 6779-6788, 2013.

14. Liang W, Xie Z, Cui W, Guo Y, Xu L, Wu J and Guan H: Comprehensive gene and microRNA expression profiling reveals a role for miRNAs in the oncogenic roles of SphK1 in papillary thyroid cancer. J Cancer Res Clin Oncol 143: 601-611, 2017.

15. Livak KJ and Schmittgen TD: Analysis of relative gene expression data using real-time quantitative PCR and the 2(-Delta Delta $\mathrm{C}(\mathrm{T})$ ) method. Methods 25: 402-408, 2001. 
16. Fry LE, Fahy E, Chrysostomou V, Hui F, Tang J, van Wijngaarden P, Petrou S and Crowston JG: The coma in glaucoma: Retinal ganglion cell dysfunction and recovery. Prog Retin Eye Res 65: 77-92, 2018.

17. Vranka JA, Kelley MJ, Acott TS and Keller KE: Extracellular matrix in the trabecular meshwork: Intraocular pressure regulation and dysregulation in glaucoma. Exp Eye Res 133: 112-125, 2015.

18. Li G, Luna C and Gonzalez P: miR-183 inhibits UV-induced DNA damage repair in human trabecular meshwork cells by targeting of KIAA0101. Invest Ophthalmol Vis Sci 57: 2178-2186, 2016.

19. Li R, Jin Y, Li Q, Sun X, Zhu H and Cui H: MiR-93-5p targeting PTEN regulates the NMDA-induced autophagy of retina ganglion cells via AKT/mTOR pathway in glaucoma. Biomed Pharmacother 100: 1-7, 2018

20. Rasmussen KD, Simmini S, Abreu-Goodger C, Bartonicek N, Di Giacomo M, Bilbao-Cortes D, Horos R, Von Lindern M, Enright AJ and O'Carroll D: The miR-144/451 locus is required for erythroid homeostasis. J Exp Med 207: 1351-1358, 2010.

21. Zhang X, Wang X, Zhu H, Zhu C, Wang Y, Pu WT, Jegga AG and Fan GC: Synergistic effects of the GATA-4-mediated miR-144/451 cluster in protection against simulated ischemia/reperfusion-induced cardiomyocyte death. J Mol Cell Cardiol 49 $841-850,2010$
22. Liu Z, Yi J, Ye R, Liu J, Duan Q, Xiao J and Liu F: miR-144 regulates transforming growth factor- $\beta 1$ iduced hepatic stellate cell activation in human fibrotic liver. Int J Clin Exp Pathol 8: 3994-4000, 2015.

23. Ruibin W, Zheng X, Chen J, Zhang X, Yang X and Lin Y: Micro RNA-1298 opposes the effects of chronic oxidative stress on human trabecular meshwork cells via targeting on EIF4E3. Biomed Pharmacother 100: 349-357, 2018.

24. Singh P, Carraher C and Schwarzbauer JE: Assembly of fibronectin extracellular matrix. Annu Rev Cell Dev Biol 26: 397-419, 2010.

25. Babizhayev MA and Brodskaya MW: Fibronectin detection in drainage outflow system of human eyes in ageing and progression of open-angle glaucoma. Mech Ageing Dev 47: 145-157, 1989.

26. Filla MS, Dimeo KD, Tong T and Peters DM: Disruption of fibronectin matrix affects type IV collagen, fibrillin and laminin deposition into extracellular matrix of human trabecular meshwork (HTM) cells. Exp Eye Res 165: 7-19, 2017.

This work is licensed under a Creative Commons Attribution-NonCommercial-NoDerivatives 4.0 International (CC BY-NC-ND 4.0) License. 